\title{
Genetic Variability of NS5B Region of Hepatitis C Virus in Togo
}

\author{
Folly Anyovi 1,2,*, Alexandre Soulier ${ }^{3,4}$, Lila Poiteau ${ }^{3,4}$, Simplice D. Karou ${ }^{5}$, Reham Soliman ${ }^{6,7}$, Jacques \\ Simpore $^{1,2}$, Stephane Chevaliez ${ }^{3,4}$, Gamal Shiha ${ }^{6,8}$. \\ ${ }^{1}$ Laboratory of Molecular Biology and Genetics (LABIOGENE), UFR-SVT, Joseph KI-ZERBO University, Ouagadougou, \\ Burkina Faso. ${ }^{2}$ Pietro Annigoni Biomolecular Research Center (CERBA), 01 BP 364 Ouagadougou 01, Burkina Faso. \\ ${ }^{3}$ Centre National de Référence des Hépatites virales B, C et delta, Laboratoire de Virologie, hôpital Henri Mondor, Université \\ Paris-Est, Créteil. ${ }^{4}$ INSERM U955, Créteil. ${ }^{5}$ Ecole Supérieure des Techniques Biologiques et Alimentaires (ESTBA), \\ Université de Lomé. ${ }^{6}$ Egyptian Liver Research Institute and Hospital (ELRIAH), Mansoura-Damietta Road, Mansoura, \\ Dakahlia, Egypt. ${ }^{7}$ Tropical Medicine Department, Faculty of Medicine, Port Said University, Port Said, Egypt. ${ }^{8}$ Hepatology \\ and Gastroenterology Unit, Internal Medicine Department, Faculty of Medicine, Mansoura University, Mansoura, Egypt.
}

\begin{abstract}
Background: Hepatitis $\mathrm{C}$ virus (HCV) infection is a major cause of chronic liver disease worldwide. The high prevalence and spread rates of the disease require serious actions to stop these rates. Determination of $\mathrm{HCV}$ genotypes and subgenotypes adds significant knowledge about the epidemiology of the disease, and provides and added value in the decision-making process of what strategy to follow and what therapy response to expert. The molecular epidemiology and genetic variability of $\mathrm{HCV}$ variant circulating in Togo still need further analysis. Materials and methods: The HCV molecular epidemiology in Togo was studies using direct sequencing and further phylogenetic analysis of a partial NS5B region of the HCV from 56 patients. HCV genotype and subtype were successfully determined in 41 out of 53. Results: The highest prevalent genotype was genotype 2 , which was found in 30 patients $(73,2 \%)$ followed by genotype 1 that was isolated from 7 patients $(17,1 \%)$, genotype 4 was isolated from 3 patients $(7,3 \%)$ and 1 patient $(2,4 \%)$ was infected by genotype 6. Conclusion: The molecular epidemiology study revealed high prevalence of genotype 2 among Togolese patients followed by genotype 1 .
\end{abstract}

\section{Introduction}

There are seven definite HCV genotypes, with whole genome nucleotide sequences differing by $30 \%$ and each can be additional subdivided into related subtypes (67 confirmed), with nucleotide sequence divergence between $15 \%$ and $30 \%{ }^{1,2}$. Viral polymerases are crucial component to the life cycle of any given virus. They initiate important roles that facilitate the consequential procession of viral replication and proper transcription of the genome of interest. Consequently, for this reason, viral polymerases present as a promising target for the design and development of potent antiviral therapies within industries focusing on pharamaceutical and medicinal chemistry ${ }^{4}$. Recently, direct-acting antiviral (DAAs) that target specific

Keywords: Hepatitis C virus, Genotype, Togo.

Received: 1-5-2021; Accepted: 18-6-2021

* Corresponding author. Email: folly.anyovi@gmail.com
$\mathrm{HCV}$ viral proteins have been developed for the treatment of chronic hepatitis $\mathrm{C}$ virus infection with an excellent safety profile and favorable clinical outcomes. These molecules include a range of non-structural (NS) NS3/4A protease, NS5B polymerase and NS5A inhibitors ${ }^{5-7}$. The NS5B polymerase is responsible for viral RNA replication, and the catalytic sit of the NS5B protein is highly conserved across the different HCV genotypes, making nucleotides inhibitors that target this protein appealing as treatment option ${ }^{8,9}$. Sequencing of a genome region divergent sufficient to discriminate type and subtypes was considered to be the most accurate method. Direct sequencing of $\mathrm{HCV}$ NS5B, Core and envelope region has proven to be reliable for classification of HCV to different genotypes ${ }^{10}$. In West Africa, preliminary results suggest a predominance of genotype 2 . Since the 5'UTR is one of the most highly conserved region of the $\mathrm{HCV}$ genome, it has historically been used for virus detection and region is now bestcharacterized regions. For practical reasons, the 5'UTR has also been chosen as the target for various genotyping test ${ }^{11-}$ ${ }^{13}$, sequencing, and the duplex mobility assay ${ }^{13}$. The aims of this study is to determine the genotypes and subgenotypes using phylogenetic analyses of HCV strains collected from chronically infected patients in Togo to establish a simple, accurate, and a reliable genotyping map for HCV diagnosis.

Materials and methods

Study Population

This study was implemented on 56 patients with chronic $\mathrm{HCV}$ infection, who were selected after a screening of NGO ASADH with TDR. The automatically serology was realized at Henri Mondor virological laboratory, which confirmed 53 samples were positive for anti-HCV antibodies and that none of the patients had co-infection with HIV or HBV. A questionnaire was provided informed consent. The data collected was processed by analysis. The samples were divided into aliquots and stored at $-70{ }^{\circ} \mathrm{C}$ and send to Paris at Henri Mondor virological laboratory.

\section{HCV RNA Extraction and HCV-NS5B amplification.}

HCV RNA extraction was carried out by using QIAsymphony DPS virus/Pathogen Midi Kit on automate 
(QIAsymphony®SP/AS version 1), following the manufacturer's instructions. The resultant HCV RNA (60 $\mu 1)$ samples were stored at $-70{ }^{\circ} \mathrm{C}$ until use. The presence of the HCV-NS5B gene was determined by nester PCR using the one step RT-PCR Master Mix Kit and the Hot start Taq plus PCR Master Mix Kit (QIAGEN) using the primers. The first round of RT-PCR amplification was performed according to the manufacturer's instructions using $10 \mu 1 \mathrm{HCV}-\mathrm{RNA}$ and $50 \mathrm{pmol}$ each of primers NS5BOAS2. The cycling conditions were as follows: a reverse transcription step for $30 \mathrm{~min}$ at $50{ }^{\circ} \mathrm{C}, 15 \mathrm{~min}$ at 95 ${ }^{0} \mathrm{C}$, followed by 35 cycles of denaturing for $1 \mathrm{~min}$ at $95{ }^{\circ} \mathrm{C}$, annealing for $45 \mathrm{~s}$ at $59{ }^{\circ} \mathrm{C}$, and an elongation step for $1 \mathrm{~min}$ at $72{ }^{\circ} \mathrm{C}$, with a final extension period of $10 \mathrm{~min}$ at $72^{\circ} \mathrm{C}$. Nested PCR using products in the NS5BIS1 and NS5BIAS2 primers was performed on $10 \mu 1$ of the sample negative for PCR products in the first round of amplification. The second round of amplification was performed with an initial 5 min preheating step at $95^{\circ} \mathrm{C}$, followed by 35 cycles of denaturing for $30 \mathrm{~s}$ at $95{ }^{\circ} \mathrm{C}$, annealing for $30 \mathrm{~s}$ at $55^{\circ} \mathrm{C}$ and elongation for $1 \mathrm{~min}$ at $72{ }^{\circ} \mathrm{C}$, with a final extension period of $10 \mathrm{~min}$ at $72^{\circ} \mathrm{C}$.

\section{DNA Purification and Sequencing.}

The PCR amplicons were purified by using Advantage 2 Kit (Advantage 2 Polymerase OZYME, France), and sequenced using the dideoxynucleotide chain termination method with the ABI PRISM®BogDye Terminator Cycle Sequencing Reaction kit (Applied Biosystems, Foster City, CA, USA). Sequence analysis was performed with the ABITM3130 Genetic Analyzer (Applied Biosystems, Foster City, CA, USA). The sens and antisens primers described above used as sequencing primers. The chromatogram sequencing files were inspected using Chromas 2.1 (Technelysium, Helensvale, Australia). The genotype of each sample was determined by comparing its sequence with those of $\mathrm{HCV}$ prototype obtained from GenBank, followed by further genetic analysis. The DNA alignment were generated with ClustalX version 2.0 software. Bootstrap analysis and phylogenetic tree were determined with MEGA software version 4.0.1 by using the neighbor-joining method. HCV genotype were classified according to the nomenclature proposed previously by Simmond et al. (2005). Sixty-four reference sequences for $\mathrm{HCV}$ genotypes and subtypes were obtained from (CNR hépatites $\mathrm{B}, \mathrm{C}$ et delta) and used constructing phylogenetic trees.

Results

The direct sequencing and phylogenetic analysis of the NS5B gene was successful in 41 out of 53 positive samples. We performed the sequencing on samples with a viral load greater than $\log ^{2}$, and so, in the case of our study, 12 samples have a viral load less than $\log 2$. The result of the study revealed that genotype 2 was the most prevalent in this population with a total number of $30(73,2 \%)$, genotype 1 was found in $7(17,1 \%)$ patients, genotype 4 was isolated from $3(7,3 \%)$ patients and 1 patients $(2,4 \%)$ had genotype 6 . The subtype was not determine in 20 patients infected with a genotype 2 strain, suggesting the existence of a new subtype not described in the literature. In fact, 20 strains of genotype 2 formed a monophyletic group independently of the other strains of the same genotype with high resampling values testifying to the robustness of the node (Figure 1). Similar results were observed for some strains of genotype 2. (Figure 1). The preliminary phylogenetic analysis containing 41 sequences was performed and allowed a selection of 86 additional (CNR hépatites B, C et delta) sequences corresponding to the most related ones to the study isolates. These reference sequences were named after their accession number, subgenotypes and country of origin. NS5B coding sequences obtained from Togolese sample were aligned with the reference sequences. The phylogenetic tree obtained by performing neighbor-joining (NJ) analysis of the alignment of sequences is shown in (Figure 1).

\section{Discussion}

To the best of our knowledge, this study is the first comprehensive research to address genotype and subgenotypes analysis of $\mathrm{HCV}$ in Togo using nucleotide sequencing.

Genotyping of $\mathrm{HCV}$ is routinely done in several countries for providing counseling regarding epidemiology and treatment monitoring ${ }^{13,14}$. In addition, the study of viral diversity provides a better understanding of the origins and dynamics of viral infections. Genetic variants of HCV are known to be widely spread around globally. Genotypes 1, 2 and 3 are found in all countries ${ }^{15}$. Comprehensive studies on the distribution of HCV genotype in west africa countries has recently published, which indicates that HCV genotype 2 was reported in about $87 \%$ in chronic HCV patients and $13 \%$ of case for genotype $1^{16-20}$. The overall data suggest that, the broad genetic diversity of genotype 2 is a characteristic of HCV infection in west Africa ${ }^{17}$. Analysis of the HCV genotype within a population is a useful epidemiological tool for study of the evolution of $\mathrm{HCV}$ infection in different geographical regions. $\mathrm{HCV}$ genotyping is also important because it provides information with regard to strain variations and potential association with disease severity ${ }^{21}$. Togo has been categorized as a country with an intermediate prevalence of $\mathrm{HCV}$ according to WHO data. HCV is still considered a major public health problem in the world ${ }^{22}$, the routes of transmitted of HCV infection in the country is surgical operations, intravenous abuse, and sexual routes.

In our study, phylogenetic analysis of the 41 currents chronic HCV patients demonstrated that, HCV-NS5B phylogenetic analysis revealed that the most prevalent genotype was HCV-2 (73,2\%), HCV-1 (17,1\%), HCV-4 $(7,3 \%)$ and HCV-6 $(2,4 \%)$ among Togolese patients with chronic HCV using HCV-NS5B sequencing analysis. 


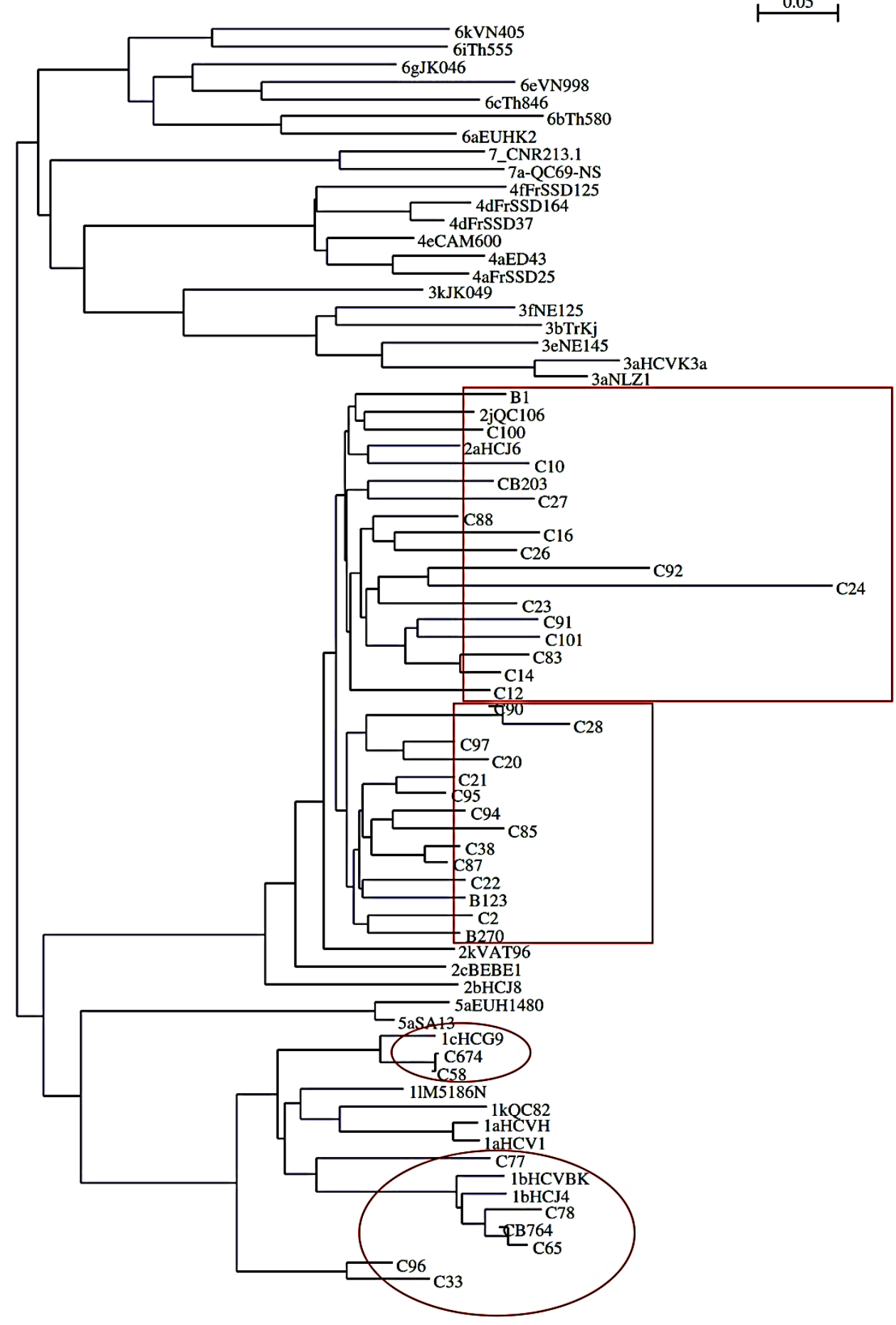

Figure 1: Phylogenetic analysis of a portion of the NS5B gene encoding RNA polymerase RNA dependent on 30 strains (boxed in red) by comparaison with strains of genotype 1-6 of the different subtypes available in the CNR hepatitis banks 


\section{Original Article}

This concord with previous observations that assumed, that HCV genotype 2 is predominant in west Africa ${ }^{17,20,23-}$ 25 . The choice of the genome region to be analyzed for identification of HCV genotypes and subgenotypes is crucial. The NS5B region is highly information of HCV in phylogenetic analysis and has received the most attention for the characterization of $\mathrm{HCV}$ isolates worldwide ${ }^{13}$. For the using pairwise distance analysis of the NS5B nucleotide sequence, we succeeded in matching $100 \%$ of amplified isolates with their specific HCV genotypes using phylogenetic tree. Pairwise analysis of the isolates from the present study belonging to the HCV-2, HCV-1 and HCV-4 genotypes revealed average specific nucleotide distance identities of $\pm 0.134,0.134$ and 0.185 , respectively, without any interference between genotype, which confirmed the outcome of our phylogenetic analysis. Numerous previous studies have designated that, the degree of accuracy of sequence variation of NS5B correlates well with HCV subtype definition, which relies on the highly informative character of specific NS5B motifs, in contrast, most classification errors caused by the use of the 5'UTR region are related to reduced discriminating power and to the absenteeism of target motifs specific for some subtypes.

Therefore, we recommend that sequence analysis of the NS5B region be used rather than 5'UTR analysis for epidemiologic studies in the future ${ }^{13,26-30}$. To distinguish HCV subtypes, primer specific PCR procedure was initially applied and that classified HCV strains into subtypes under genotype 2. Sequence-based characterization by phylogenetic analysis, however, showed an identical clustering of the Togolese isolates under genotype 2, but the isolates exhibited high genetic variability and appeared distinct from previously described subtypes of HCV 2 . Furthermore, the subtype couldn't be determined in 20 patients infected with $\mathrm{HCV}-2$ strains suggesting the existence of a new subtype not yet described in the literature. Indeed, 20 strains of genotype 2 formed a monophyletic group independently of the other strains of the same genotype with high resampling values testifying to the robustness of the node. Similar clustering was detected in Ghanaian cluster ${ }^{22}$ and other studies. The phylogenetic analysis showed that the distribution of HCV Togolese strains described here was almost starlike within genotype 2. There are possible biological interpretations for this tree shape. The recent and rapidly expanding epidemic of HCV type 2 in Togo. Unequal evolutionary rate among the different genotypes of HCV have been reported, and HCV genotype 2 appears to evolve faster than the average of the other genotypes ${ }^{17,31}$.

However, no epidemiological data are supporting the hypothesis is that, an ancient endemicity of HCV type 2 in Togo and probably in West Africa led to the emergence of an undifferentiated multiplicity of subtypes over a longterm evolution process. A similar endemic spread seems to have occurred in the India subcontinent with genotype 3 and in Southeast Asia with genotype 6. HCV type 3 and 6 include a great number of subtype characterized by extensive sequence variability ${ }^{17}$. In future, the study should aim at initially screening a much larger number of samples from different region of Togo, in order to obtain a more significant number of positive cases that can describe the genetic diversity of prevailing HCV genotype in Togo. Also, the use of new technology such as pyro or ultra-deep sequencing, which has higher capacity than direct sequencing in detecting both minority pathogen populations and presence of dual or multiple infections, would very useful in analyzing $\mathrm{HCV}$ especially in a region where the virus appears to be endemic and several subtypes may be in circulation ${ }^{22}$. Further study is warranted to elucidate the $\mathrm{HCV}$ subtype profile and to define reliable means of subtype Togolese HCV strains. An in-depth analysis of nucleotide sequences of at least two coding regions, or preferably the entire HCV genome, may yield better results.

Conclusion

Our results showed that the most common $\mathrm{HCV}$ genotype circulating in Togo were genotype 2, 1, 4 and 6. Moreover, our study confirmed that HCV-NS5B gene sequence analysis provides precise genotype and subtype identification and an accurate epidemiological representation of circulation viral strains. Overall, the mosaic pattern of the sequences observed in this study depict extremely high genetic diversity of the predominant genotype. This may shed some light on earlier findings that suggest that HCV genotype 2 is indigenous to Togo.

\section{References}

1. Smith, D. B., Bukh, J., Kuiken, C., et al. (2014). Expanded classification of hepatitis $\mathrm{C}$ virus into 7 genotypes and 67 subtypes: updated criteria and genotype assignment web resource. Hepatology, 59(1), 318-327.

2. Quer, J., Gregori, J., Rodríguez-Frias, F., et al. (2015). High-resolution hepatitis $\mathrm{C}$ virus subtyping using NS5B deep sequencing and phylogeny, an alternative to current methods. Journal of clinical microbiology, 53(1), 219-226.

3. Elmetwalli Alaa, Esmael, Ahmed and Amer, Mahmoud. (2019). Role of serum miRNA-500 as a biomarker of hepatocellular carcinoma (HCC) progression with hepatitis $\mathrm{C}$ virus infection. Nature and Science. 17. 29-36. 10.7537/marsnsj170919.04.

4. Sesmero, E., and Thorpe, I. F. (2015). Using the hepatitis C virus RNA-dependent RNA polymerase as a model to understand viral polymerase structure, function and dynamics. Viruses, 7(7), 3974-3994.

5. Mousa N, Abdel-Aziz M, Farag R, et al. (2018). Recent trends in chronic hepatitis $\mathrm{C}$ virus treatment. Med J Viral Hepatitis. 2018; 2 (2), -pp. 1-6.

6. Dina, E., Nasser, M., Sarah, E., et al. (2020). Pretreatment serum alpha fetoprotein and its relation to sustained virologic response in patients with chronic $\mathrm{HCV}$ infection treated with direct-acting antiviral therapy. Medical Journal of Viral Hepatitis, 4(2), 6973. 
7. Shiha, G., El-Basiouny, M., Soliman, R., et al. (2016). Sofosbuvir plus ribavirin for treatment-naive chronic $\mathrm{HCV}$ genotype 4 patients: real-life experience. Medical Journal of Viral Hepatitis (MJVH), 2-8.

8. Sofia MJ, Bao D, Chang W, et al. (2010). Discovery of a $\quad \beta$-D-20-Deoxy-20-r-fluoro-20- $\beta$-C-methyluridine Nucleotide Prodrug (PSI-7977) for the Treatment of Hepatitis C Virus. Journal of Medicinal Chemistry. 53:7202-7218.

9. Stedman, C. (2014). Sofosbuvir, a NS5B polymerase inhibitor in the treatment of hepatitis $\mathrm{C}$ : a review of its clinical potential. Therapeutic advances in gastroenterology, 7(3), 131-140.

10. Fakhr, A. E., Pourkarim, M. R., Maes, P., et al. (2013). Hepatitis C virus NS5B sequence-based genotyping analysis of patients from the Sharkia Governorate, Egypt. Hepatitis monthly, 13(12).

11. Stuyver, L., Wyseur, A., van Arnhem, W., et al. (1995). Hepatitis $C$ virus genotyping by means of $5^{\prime}$-UR/core line probe assays and molecular analysis of untypeable samples. Virus research, 38(2-3), 137-157.

12. Stuyver, L., Wyseur, A., van Arnhem, et al. (1996). Second-generation line probe assay for hepatitis C virus genotyping. Journal of Clinical Microbiology, 34(9), 2259-2266.

13. El Hadad, S., Al-Hamdan, H., and Linjawi, S. (2017). Partial sequencing analysis of the NS5B region confirmed the predominance of hepatitis $\mathrm{C}$ virus genotype 1 infection in Jeddah, Saudi Arabia. PloS one, 12(5), e0178225.

14. Cantaloube, J. F., Laperche, S., Gallian, P., et al. (2006). Analysis of the $5^{\prime}$ noncoding region versus the NS5b region in genotyping hepatitis $C$ virus isolates from blood donors in France. Journal of clinical microbiology, 44(6), 2051-2056.

15. Mellor, J., Holmes, E. C., Jarvis, L. M., et al. (1995). Investigation of the pattern of hepatitis $\mathrm{C}$ virus sequence diversity in different geographical regions: implications for virus classification. Journal of General Virology, 76(10), 2493-2507.

16. Jeannel, D., Fretz, C., Traore, Y., et al. (1998). Evidence for high genetic diversity and long-term endemicity of hepatitis $\mathrm{C}$ virus genotypes 1 and 2 in West Africa. Journal of medical virology, 55(2), 9297.

17. Candotti, D., Temple, J., Sarkodie, F., et al. (2003). Frequent recovery and broad genotype 2 diversity characterize hepatitis $\mathrm{C}$ virus infection in Ghana, West Africa. Journal of virology, 77(14), 7914-7923.

18. Victor Max Corman, Adam Grundhoff, Christine Baechlein, Nicole Fischer, Anatoly Gmyl, Robert Wollny1, Dickson Dei8, Daniel Ritz, Tabea Binger, Ernest Adankwah, Kwadwo Sarfo Marfo, Lawrence Annison, Augustina Annan, Yaw Adu-Sarkodie, Samuel Oppong, Paul Be JFD. Highly divergent hepaciviruses from African cattle. American Society for Microbiology. 2015. doi:10.1128/JVI.00393-15
19. Maaroufi, A., Vince, A., Himatt, S. M., et al. (2017). Historical epidemiology of hepatitis $\mathrm{C}$ virus in select countries-volume 4. Journal of viral hepatitis, 24, 824.

20. Assih, M., Ouattara, A. K., Diarra, B., et al. (2018). Genetic diversity of hepatitis viruses in West-African countries from 1996 to 2018. World journal of hepatology, 10(11), 807.

21. García-Montalvo, B. M., and Galguera-Colorado, P. L. (2008). Distribution of hepatitis C virus genotypes, risk factors and liver disease in patients from Yucatan, Mexico. Annals of Hepatology, 7(4), 345-349.

22. Nii-Trebi, N. I., Brown, C. A., Osei, Y. D., et al. (2019). Core encoding sequences of Hepatitis $\mathrm{C}$ virus in Ghanaian blood donors are predominantly mosaics of different genotype 2 strains and cannot distinguish subtypes. BMC infectious diseases, 19(1), 1-11.

23. Forbi, J. C., Purdy, M. A., Campo, D. S., et al. (2012). Epidemic history of hepatitis $\mathrm{C}$ virus infection in two remote communities in Nigeria, West Africa. The Journal of general virology, 93(0 7), 1410.

24. Shenge, J.A., Odaibo, G.N., Olaleye, D. O., et al. (2019). Phylogenetic analysis of hepatitis $\mathrm{C}$ virus among HIV/ HCV co-infected patients in Nigeria. PLoS ONE, 14(1)-10.

25. Candotti, D., Sauvage, V., Cappy, P., et al. (2020). High rate of hepatitis $\mathrm{C}$ virus and human immunodeficiency virus false-positive results in serologic screening in sub-Saharan Africa: Adverse impact on the blood supply. Transfusion, 60(1), 106116.

26. Morice, Y., Roulot, D., Grando, V., et al. (2001). Phylogenetic analyses confirm the high prevalence of hepatitis C virus (HCV) type 4 in the Seine-Saint-Denis district (France) and indicate seven different HCV-4 subtypes linked to two different epidemiological patterns. Journal of General Virology, 82(5), 10011012.

27. Martial, J., Morice, Y., Abel, S., et al. (2004). Hepatitis $\mathrm{C}$ virus (HCV) genotypes in the Caribbean island of Martinique: evidence for a large radiation of $\mathrm{HCV}-2$ and for a recent introduction from Europe of $\mathrm{HCV}$ 4. Journal of clinical microbiology, 42(2), 784-791.

28. Cantaloube, J. F., Gallian, P., Attoui, H., et al. (2005). Genotype distribution and molecular epidemiology of hepatitis $\mathrm{C}$ virus in blood donors from southeast France. Journal of clinical microbiology, 43(8), 36243629.

29. Simmonds, P., Bukh, J., Combet, C., et al. (2005). Consensus proposals for a unified system of nomenclature of hepatitis $\mathrm{C}$ virus genotypes. Hepatology, 42(4), 962-973.

30. Baclig, M. O., Chan, V. F., Ramos, J. D. A., et al. (2010). Correlation of the $5^{\prime}$ untranslated region $\left(5^{\prime}\right.$ UTR) and non-structural 5B (NS5B) nucleotide sequences in hepatitis $\mathrm{C}$ virus subtyping. International journal of molecular epidemiology and genetics, 1(3), 236. 
31. Salemi, M., and Vandamme, A. M. (2002). Hepatitis C virus evolutionary patterns studied through analysis of full-genome sequences. Journal of molecular evolution, 54(1), 62-70. 